\title{
Primary Head Teachers' Construction and Re-negotiation of Care in COVID-19 Lockdown in Scotland
}

\author{
Peter Ferguson, Megan McKenzie, Daniela Mercieca*, Duncan P. Mercieca and \\ Lesley Sutherland
}

School of Education and Social Work, University of Dundee, Dundee, Scotland

OPEN ACCESS

Edited by:

Monica Byrne-Jimenez, Michigan State University,

United States

Reviewed by:

Christa Boske,

Kent State University, United States lan Potter,

GFM Education, United Kingdom Karen Edge,

University College London, United Kingdom

*Correspondence: Daniela Mercieca dmercieca001@dundee.ac.uk

Specialty section This article was submitted to

Leadership in Education, a section of the journal

Frontiers in Education

Received: 15 October 2020 Accepted: 05 March 2021

Published: 31 March 2021

Citation:

Ferguson P, McKenzie $M$,

Mercieca D. Mercieca DP and Sutherland L (2021) Primary Head

Teachers' Construction

and Re-negotiation of Care

in COVID-19 Lockdown in Scotland.

Front. Educ. 6:617869.

doi: 10.3389/feduc.2021.617869
This article looks at three primary Head Teachers' experience of working in COVID-19 lockdown in Scotland. The theoretical framework of this paper builds on Nel Noddings' ethics of care, with a particular focus on reciprocity, empathy, communication, and community. The three Head Teachers were interviewed during the pandemic lockdown. These interviews are part of a larger study that interviewed teachers and Head Teachers during COVID-19 lockdown in Scotland, asking how this lockdown challenged and influenced their identity as educators. The focus on care is important as during lockdown in Scotland the focus of home learning was on pupils and families' well-being and care, rather than on performative acts of learning. This paper argues that the pandemic provided an alternative space for the Head Teachers to re-negotiate their caring role and identity in their understanding of being an educational leader.

Keywords: COVID-19 lockdown, Head Teachers, Scotland, ethics of care, Nel Noddings, reciprocity, empathy, communication

\section{INTRODUCTION}

As human beings we want to care and to be cared for. Caring is important in itself... Why care about caring? (emphasis in original, Noddings, 1986, p. 7)

COVID-19 lockdown has challenged some of the concepts which are fundamental in schooling and its systems. Under normal circumstances, caring is implicitly part of the educational and schooling experience for both children and staff (see Edge et al., 2016; Smylie et al., 2016). Research shows that caring leadership is related to improved attainment (Louis et al., 2016; Scottish Government, 2021). Prior to the COVID-19 pandemic, a review conducted by Scottish Government (2018) considered multiple dimensions relating to the health and well-being of children, including caring relations in education, and found positive practices embedded across all levels of the education system. However, the physical distance created by the closure of school buildings and the social restrictions placed on communities due to COVID-19 lockdown put the caring aspect of education and schooling into sharp focus as there was a sudden concern about how schools could fulfil their fundamental caring role for children, families, and communities (Sergiovanni, 1999) when not all parties could be easily or consistently reached. Efforts were immediately made to set up connections so that learning and consolidation of content could be continued. Yet the idea of caring, so much more ephemeral and difficult to operationalise, needed more active, more 
direct thought than before, where learning was just one manifestation of that care. We realised in shock that we had been complacent about physical presence and the ability to show caring to each other by being close to one another, by looking into each other's eyes, by smiling, and even by physical touch. In Scotland, the national framework for child well-being; "Getting It Right for Every Child” (GIRFEC) has successfully supported families during a typical school year (Coles et al., 2016). However, the closure of schools challenged such frameworks. How, then, could schools and educators reach out in caring to children and families when in lockdown?

This article is based on a larger study carried out by a group of researchers at the University of Dundee. It aimed at addressing the following research question: What are primary school educators' experiences of teaching from home/in hub during the Covid-19 lockdown in Scotland? This article analyses three indepth interviews with Head Teachers of Scottish primary schools in relation to Nel Noddings' ethics of care.

The next section gives a brief context to set the scene for this article. This is followed by an explanation of the method rationale, a general overview of Noddings' writing about care, and the emerging themes from the data.

\section{SCOTTISH CONTEXT}

The student population in primary schools in Scotland varies considerably. A few large city primary schools may have around 700 pupils, whilst in a rural setting, the pupil population may be as low as single figures. Scotland has a high number of small or very small schools, often representing the scattered mainland and island population of the nation. In all settings, Head Teachers (Principals) must develop a clearly defined strategic plan for their individual school improvement. In addition to the school improvement, curriculum development, and implementation of an effective learning strategy, Head Teachers have responsibility for pupil and staff well-being and performance, property finances, elements of professional development programmes, and for the development of family and community relationships. Unlike other parts of the United Kingdom, Scottish Head Teachers are not directly accountable to school governors, but rather, to the Local Authority. In practice, the smaller the school, the fewer layers of leadership (usually a Depute Head or a Principal Teacher) between the Head Teacher and students. Conversely, in the large school, the frequency with which pupils meet with the Head Teacher may be greatly reduced. Ultimately, school leaders at all levels will be tasked with developing community both within the school and with partners from professional agencies, businesses, and locally elected Council members. Reflecting a democratic structure, the Scottish system of Local Authority organisation means that schools are also guided by and are accountable to education professionals who in turn respond to the elected council members (Counsellors).

Schools in Scotland function within a national policy framework developed since 2006. "GIRFEC" embeds the articles of UNCRC to promote and support in practice the care and well-being of all children and young people. GIRFEC is central to all government policies which support children, young people, and their families. The aim of GIRFEC is to provide a coordinated, streamlined, and holistic approach to supporting families wherein children and young people receive "the right help, at the right time, from the right people" (Scottish Government, 2008), to ensure they grow and develop to reach their full potential. Referring to what are known as the SHANARRI indicators (safe, healthy, achieving, nurtured, active, respected, responsible, and included) (see Scottish Government, 2008), the principles and values underlying GIRFEC are the focus on the child, the idea that well-being is contextually situated the aim to be proactive rather than reactive, and the necessity of a coordinated approach. In this regard, the benefits of direct contact with children, families, and GIRFEC partners came under immediate threat with the announced closure of all Scottish schools in response to the Covid-19 pandemic. The Deputy First Minister in Scotland announced that all local authority schools and nurseries would close from the end of the school day on Friday March 20, 2020. It was recognised that there was a need for childcare provision during this time for both children of key workers and vulnerable children. This care was organised and provided at what became known as education hubs. These hubs were set up at selected educational establishments and were accessed by children and families linked to the area or school cluster. They were run by school staff from the cluster of schools in the area on a rota basis.

Local authorities (school districts) and schools in Scotland had to decide how best to move forward with children learning from home to ensure that teaching and learning continued during this lockdown. This included online learning. The majority of local authorities access digital learning platform such as Glow or Seesaw which allows access to Microsoft Office, Teams, or Google Classroom. Some individual schools received local authority guidance as to expectations on how schools could facilitate home learning, but this was not immediate for all, so that some schools had the space where they autonomously make decisions and took action to provide teaching, learning, and care as they deemed to be effective for their pupils. This meant that there has been a variety of experience for schools and learners when teaching and learning during the COVID-19 pandemic lockdown and ensuring the care and well-being of their pupils.

\section{METHODOLOGY}

As past teachers and Head Teachers and currently trainers of teachers and Head Teachers, indeed, as parents of children who attend schools, we were acutely aware of the flurry of activity going on in schools in March 2020 as it became increasingly clear that school closure was imminent. Our own realities, personal and professional, needed to be adjusted, yet our thoughts about embarking on this research project were motivated by the wish to pause and ask educators for their stories. We authors are part of a larger group of researchers from the School of Education and Social Work at the University of Dundee, all of whom were keen to capture the impact of this unprecedented event on the lives of children, their families, and educators. A decision was 
taken to carry out qualitative research with teachers and Head Teachers working in Scottish primary schools, reluctantly making the decision not to pursue the stories of educators in High Schools or those of families and children. Such a choice was based on the knowledge of the kind of data that we wanted to gather, which gave detailed insights into the lived experiences of those agreeing to be interviewed. We could not ethically gather more data than we could realistically manage to analyse, although the availability of it was tantalising.

Following ethical clearance from the University of Dundee, teachers and Head Teachers in Primary schools in Scotland were invited through different social platforms to participate in an indepth interview to capture their lived experiences in real time. These online interviews were carried out through MS Teams, starting from the second week of lockdown until the end of the scholastic year in June 2020, and addressed the following research question mentioned in Section "Introduction."

We were "curious" about their lived experiences and about their understanding of the impact of these experiences on their identity as teachers. The research thus aimed to capture their perceptions of their current experiences of work and the contribution of this to their thinking about what is valued in their work as a teacher or Head Teacher as they supported children and families during the lockdown. Ten questions guided the interviews, with the interviewers reporting that most participants needed little prompting as they were very articulate and fluent. Some participants reported that they welcomed such conversations and thought that it gave them space to pause and reflect on what they were engaging in in unique times, a chance to take stock even on all that they had accomplished in a short span of time and under intense pressure. More than 60 primary school teachers and Head Teachers volunteered to participate in the project and were interviewed, after which the painful process of transcription was started. It is important to point out that due to the urgency of the research, it was not possible to delay the start of data collection until a proposal could be submitted to apply for research funding, which would cover costs of making the recorded data ready for analysis. This meant that transcription relied on the availability of time of the individual researchers, which varied depending on their circumstances.

The respondents volunteered themselves as participants and all those who did, and who fit the parameters of working in primary schools in Scotland, were accepted. The research group was not after a representative sample of educators which was distributed according to certain criteria. Although cognizant of the large variety of contexts in which Scottish schools in different geographical and socio-economic areas function, we were not seeking a sociological understanding of their experiences, as much as we sought the educators' personal thoughts about these experiences. We did not claim to be able to generalise our findings to represent the experience of all primary school educators. As Wendy Hollway (1989) suggests, "generalizability... [in this kind of research] ... has to be established according to theoretical rather than statistical principles" (p.16). In the Rogerian sense of what is most personal is most general, we believe that the issues emerging from our process of analysis (explained below) are generalisable conceptually and theoretically. We have had several reports in our online seminars about this project that viewers have resonated with the participants' expressed thoughts and feelings (Rogers, 2001, p. 26).

The process of analysis can be visualised in the form of two spirals which seem to weave closer and closer together as they progress. These are constituted by our reading of Nel Noddings and our listening to and transcribing of the interviews of these three Head Teachers. As interviewers discussed their interviews with those leading the research project, it became evident that three Head Teacher interviews were strongly founded on ideas of care. The authors of this paper embarked on reading about the ethics of care, while at the same time becoming more and more immersed in the data. As Hollway and Jefferson (2000) stress, "after a whole day working on the transcripts ... (a process we often referred to as 'immersion') we would be inhabited by that person in the sense that our imagination was full of him or her" (p.69). The authors met online several times to discuss their thoughts about the literature read and the interviews, and started to explore themes that emerged, following Hollway's idea that the significance of the interviews is not only "a property of the extract, but of the work it is put to do" (Hollway, 1989, p. 36). This was thus a theory-led thematic analysis (Hayes, 1997) based on the works of Noddings (Noddings, 1986, 2005, 2012a,b), where both theory and interviews were "speaking" to each other while at the same time challenging each other. This influenced the structure of this paper, with no distinction between findings and discussion, but rather themes with merging data and theory, thus "making complex" the lived experiences of the Head Teachers.

A last point about interviewing educators who volunteered: we are aware of the possibility of these respondents presenting as models of hard work and enthusiastic professionalism. We have mentioned elsewhere that these need to be seen as experiences of people willing to share their story and that there are others whose stories may not tally. Yet, there have been many who have "recognised" our interpretations and analyses, "that is, the sense that we made out of them can be shared through the subjectivity of others" (Hollway and Jefferson, 2000, p. 80) "Our work, as well as being theoretically led, is solidly empirical in the sense that supporting and challenging evidence is available" (Hollway and Jefferson, 2000, p. 80).

Introducing the three Head Teachers: Mhàiri works in a large school in one of Scotland's cities. The school is very multi-cultural and many of the families score high on the Scottish Index of Multiple Deprivation (indicating a certain level of privilege). Emily works in an average sized school in a town in Scotland. The school population is not diverse, and most of the families are of Scottish origin. Several families score lower on the SIMD (this means that they experience some form of deprivation). Agnes lives and works on one of the small islands in Scotland. This brings to the article a discourse that is not often heard about the experiences of educators working in such places. Her community is very tightly knit, where all know each other. Many families score high on the SIMD. There are similarities between the three Head Teachers: all three fit in the age bracket between later thirties and early forties (see Edge et al., 2016 on Generation X School Leaders) and they have been Head Teachers for around 5 years. 


\section{INTRODUCING ETHICS OF CARE}

For Noddings, life is always relational and her work is based on this perspective. The starting point, as well as the process of ethics of care, is the "caring relationship" (Noddings, 2012a, p. 4) where the focus should be on spending time building a relation of care and trust. This is not time wasted (see Noddings, 2012b, p. 777) as Noddings emphasises that continually taking time to create and maintain a caring relationship "is underneath all we do... When that climate is established and maintained, everything else goes better" (Noddings, 2012b, p. 777). A relational ethics of care always assumes a carer and the cared-for. We cannot think of these roles as static, for what establishes these roles is the moment(s) of encounters. The one who is attentive to the other becomes the carer for the cared-for. The carer is "attentive: she or he listens, observes, and is receptive to the expressed needs of the cared-for" (Noddings, 2012a, p.4). As Yiannis Gabriel (2015) argues, ethics of care is "an ethics that emphasises the inter-relatedness of human beings and highlights the importance of attentiveness, empathy, responsiveness, and responsibility for others" (p.317). It is the response that the carer and cared-for give to each other that is important in this relationship of care. The cared-for needs to respond to the care given, to acknowledge, even if this is at a very basic level. The example that is commonly given is the baby who stops crying as soon as the baby is held by an adult. "Without this response there is no caring relation no matter how hard the carer has worked at it" (emphasis in original, Noddings, 2012a, p.4). The response provides the building blocks for the construction of a continuing caring relationship. These ideas are expanded on throughout this paper as they help us read the data emerging from the Head Teachers' interviews. Four themes: reciprocity, empathy, communication, and community, are developed in the next section.

\section{THEMATIC ANALYSIS AND DISCUSSION}

\section{Reciprocity}

We start this theme with excerpts from the interviews about the days when these Head Teachers were faced with impending school closure. They are rather lengthy but we strongly feel that they set the scene for the focus of care as it emerged and developed over the 4 months of school closure. These excerpts also introduce the Head Teachers and their contexts.

Mhàiri: The kind of run up to lockdown ... Northern Ireland had announced that schools were closing. I think that was the Wednesday, Thursday, and Friday, which was a week before the Scottish Government announced we were going to lock down... we were waiting for the Local Authority to kind of give us guidance and I met my management team every day that week about how we might prepare and what we might do. And we'd all agree that we're just going wait on what the Local Authority is telling us how we were going to communicate with people, what we should do, how we should prepare. And then by the end of the week, we hadn't yet received any guidance, so I kind of freaked out, you know, in the nicest possible way. And then in the weekend came up with a plan. On the Monday every member of staff kind of met. We gave them what they had to do by the Monday Tuesday Wednesday Thursday Friday. We had $100 \mathrm{~h}$ of parents volunteering that worked at getting packs ready. We got MS TEAMS all up and running within that week. We produced our own guidance as a school on how we were going to do learning from home and I'm really glad we did that... So I'm really glad that I had that, you know, kind of level of panic to say "no, we're definitely closing and we need to respond. We're just gonna do our own thing and if it's not what the Local Authority want, well then, we'll react and respond and change." Our whole kind of ethos throughout this is that the children need to feel connected to us whether or not they're hearing us or they're seeing us and then starting this week and into the next week all class teachers and PSA's will be making phone calls to children.

Emily: That week everybody knew that something was going to happen and we put an appeal out to our school community at that point and were absolutely overwhelmed by what came in [food for food parcels] so we've got that to keep us going and a nice little story as well, it was on the news as well, we've got a wee girl, one of our pupils, cycled last week 25 miles every day in the house on an exercise bike, and then on the Friday she did a double one so she did 50 miles on the Friday and she's raised over a thousand pounds which she's given that so we can go to the shops and buy more food... Before schools closed we had a really clear system within school of how you pass on well-being concerns and who does that and I've kind of just tried to replicate that but adapted it to this situation, so that it's the same people. So everybody in our school community has got the responsibility of picking up pastoral well-being concerns but then those are really fed in through a well-being form and they come and we have a well-being meeting and then we decide what the action is, using staff to do all those check ins or to check in on the families. Agnes: Before we broke up I created a list of vulnerable children. We looked literally all down from nursery and one by one, looked at what's happening in each family and do they need someone to be checking in. I just split the list that way and also those that we have the best rapport with. So whether that might have more to do with our support for the learning hub, whether they have more to do with our well-being centre, whether they actually have more to do with mainstream. We also had conversations with our medical link, our social worker, health worker, and then with the other school nurse as well-created a list. And we have a system in place that the staff create a log of what contact they have had and they send it to me each Friday and so we put it on the system. But I've left it up to each member of stuff to say who's on the list. They know best whether to have one contact a week or whether it needs to be daily. What's going to be the most appropriate way of doing that, and what that child needs? So, for example, one of the children on my list is extremely overweight. I have 
been running a version of the Jumpstart program and we had some conversations with the National Health Service and the families. They'll be making sure that I'm sending little reminders and motivations, etc., to try to get him out and about during COVID-19. If he could lose some of the weight and exercising, then that would be fantastic.

As already evident, the caring relation with reciprocity was reflected throughout the interviews, particularly when the Head Teachers mentioned their teachers, the pupils, and their families. The Head Teachers' role seems to have been one of encouragement, support, and also sometimes an intermediary. This was partly to support the construction of a relation of care online, but the emphasis was more importantly placed on the maintenance of this relation over a long period of time. The positions of these actors relative to each other shifted in this new set up of the caring relation. Whereas teachers and Head Teachers had easy access to pupils because of their physical presence before lockdown with parents/carers relatively in the background, following the physical closure of schools, children in primary schools could only be accessed through the medium of their families. These families needed to actively set up connections, especially those that were technical, and also needed to dedicate time sustainably to support their children. Before lockdown, procedures were in place, even very basically through legislation, to ensure that children connected to schools. However, the novelty and unexpectedness of this situation lacked such infrastructure, so that much depended on the ability, willingness, time-availability, resources, and technical knowhow of families so that children could be accessed. The Head Teachers interviewed mention that many families responded to this newly established relationship positively, not only by enabling access and supporting it actively, but also celebrating what they perceived as their own increased participation in their child's school life. One Head Teacher referred to the weekly online assembly she organised and mentioned comments that families sent her to this effect. She reported that parents and carers asked to continue to be sent online links so that their increased presence could be sustained after lockdown as they reported feeling more part of the school. This is quite a contradiction, albeit a happy one, that the set-up of the virtual school because of physical distance enabled more parental belonging and engagement than was thought possible before the closure of the school building. Noddings argues, that when sharing occurs, it is easier to care (1986, p. 72). This seems to be the case here.

One Head Teacher's emphasis on maintaining this relation of care was also reflected in her insistence to continuously create new reasons for families and the school to connect. She tried to have new ideas to share with families or projects to start every two weeks and even created videos of herself and staff dancing to routines or sharing human or humorous moments. The professional and personal boundaries were blurred as families saw teachers dancing in their living rooms (McLennan et al., 2020). It was as though since pupils had receded, so to speak, to their respective homes, the staff's reach to these pupils needed to start from their homes too. It seemed the staff tried to nullify the longer distance to the pupil by entering the pupils' homes through the screens. This needed careful negotiation of Local Authority regulations, union directives, concerns about privacy of staff and families, as well as consideration of the time. This latter mention of time merits emphasis, as claims increased on parents' and carers' time to support their children's online access and engagement with allocated "school” tasks carried out at home.

The data highlighted that teachers and Head Teachers, also parents and carers, grappled with the issue of time. Nonetheless, the interviews evidence an effort on the part of these Head Teachers to maintain a relationship with students, particularly those that were considered vulnerable and needed further support. All the Head Teachers mentioned that there was a very small group of children who were "hard to reach." The sense of helplessness and concern in their tone of voice during the interviews reported of a lack of response and reciprocity from these families. While the reciprocal is central to the caring relationship, Noddings makes it very clear that we cannot demand it:

To accept the gift of responsiveness from the cared-for is natural for the one-caring. It is consistent with caring. To demand such responsiveness is both futile and inconsistent with caring. The one-caring is motivated in the direction of the cared-for and she must, therefore, respect his freedom. She meets him as a subject-not as an object to be manipulated nor as a data source. Indeed, this recognition of the freedom-as-subject of the cared-for is a fundamental result of her genuine receiving of the cared-for (Noddings, 1986, p. 72).

Were the Head Teachers hoping and expecting some form of responsiveness from these pupils and their families? This might be the case. We need to remind ourselves that educational discourse is imbued with references that "all" children will make it and be successful. The Scottish perspective on education has largely rejected the Anglo-American historical tendency to separate care from learning (Smith, 2013), but has embraced both a Scandinavian and historically Scottish tradition (Kilbrandon, 1964). Although principally a response to youth justice, this intentional desire to blur the lines between home, school, professional, and personal (Smith, 2013) is now manifest in the ethos of GIRFEC (Scottish Government, 2016), Scotland's framework for well-being for all young people. In tandem with the GIRFEC intention is the responsibility and requirement of all teachers to fulfil the professional standards laid down by the General Teaching Council for Scotland (2012, p. 6), "Providing and ensuring a safe and secure environment for all learners within a caring and compassionate ethos and with an understanding of well-being." This sense of care and wellbeing is extended to families and communities within the same lists of professional standards. As part of this on-going discourse (Scottish Government, 2016), teachers and schools feel responsible to help bring this about for all pupils. One could see these "hard to reach" pupils and families (we pause for a minute and reflect on the deficit language that we ourselves are using to refer to these families, as this too does not enable Noddings' freedom) as posing a challenge of continually trying and striving 
to achieve a reciprocal caring relation. It is interesting that two of the Head Teachers mentioned personal experiences that reflected vulnerability in their lives. While we do not feel that we can recount these experiences in this paper for the sake of anonymity of the Head Teachers, they both seem to identify themselves with these pupils and their families. This leads to the next theme which expands on the attentive listening and empathy in the following section.

\section{Empathy and Listening}

The motivation to care is driven by empathy, being able to empathise through feeling and understanding a circumstance or sympathising by feeling for someone (Noddings, 2012a, p. 54). The focus of "feeling with" (Noddings, 2012a, p. 55) is central here to Noddings' argument, who wants to move away from an understanding of empathy that only involves cognitive function. The term empathy can be used to describe a "reading" of the other through feelings and understanding (see Noddings, 2012a, p. 55). Listening (see Noddings, 2012a) is an essential factor in empathy. Caring is framed around both needs that are expressed, as well as those needs that carers assume in the cared-for (Noddings, 2012b, p. 772). While assumed needs and expressed needs complement each other, Noddings places a lot of emphasis on the latter. She argues that "we must listen, not just 'tell,' assuming that we know what the other needs" (p. 773). This listening to the expressed needs of the other, that is, the affective condition of the other is what "moves us" (p. 773). The interviews reflect a constant negotiation between assumed needs and expressed needs, and the desire to find a balance to maintain a reciprocal relationship.

The long excerpt from the interviews earlier in this paper highlights the reaction of the Head Teachers as they waited for clear guidance from their Local Authorities about what learning at home should look like. In the absence of this direction at the time when they felt it necessary, Mhàiri took matters in her own hands and proactively asked families what they needed to setup home learning, whether it was items like pencils and glue or a resource like a tablet. She took account of expressed needs and with a team of family helpers, learning packs were made to meet these needs alongside generic items, such as a letter from the class teacher and a jotter, perhaps the assumed needs, to provide reassurance to children and families. In her interview, she describes the message she has conveyed to families and will continue to throughout this time, "If you're struggling, email us and we'll get in contact with you" where she invites families to express needs so that the school can show care and support them, recognising the many different home circumstances arising at this time. Mhàiri describes a film she was planning to make to send to families to reassure them where the message will be: "We didn't expect to be in this situation. We're all doing the best we can and that's how you move forward and you get in contact with us if you need help."

Noddings describes that when "the one-caring is engrossed in the cared-for [, she] undergoes a motivational displacement towards the projects of the cared-for... [This means] that onecaring receives the other, for the interval of caring, completely and non-selectively. She is present to the other and places her motive power in his service" (Noddings, 1986, p. 176). The notion of motivational displacement appears too in caring leadership literature as a key characteristic of caring relations (see Louis et al., 2016). Mhàiri here places herself and her staff in the service of the pupils and their families. An interesting observation emerging from Mhàiri's interview is about the role of the teacher's union. The latter tried to restrict the actions of teachers to prevent them feeling over-burdened by demands placed during the lockdown. Yet members of staff seem to have been torn by their wish to reach out and their wish to observe the guidance issued by their union. According to this Head Teacher, she was looking out for her staff, and was dismayed that their efforts were stopped by union directives.

The pastoral ones and the child protection ones, I make, along with my deputes. The check in ones that we tried to make the next couple of weeks were to be made by the class teachers and pupil support assistants. Now what wasn't helpful was, we agreed 2 weeks ago as a staff team that we were going to contact our children, and it just going to be a "hi, how are you?", and then the union issued guidance last week which basically said that teachers shouldn't be making routine phone calls, that it should be a management thing, that they should have proper training. That has set us back and it was really unhelpful. When enquiries were further made the union said that they wouldn't stop staff calling. But they put it out there, the Local Authority said again that teaching staff can call if they want. But that set me back slightly, so the union wasn't helpful because what they have stopped is kindness and they stopped connection with children, they stopped the rhythm of attachment that we built up in our school. So it was really unhelpful actually (Mhàiri).

Emily reported that they supported families who approached the school for help and also followed them up regularly, also showing care as a response to the families' expressed need.

We've put out a lot of literature on the kindness hashtag on Twitter to say "do you need help"... you know, we've made pastoral phone calls, we've tried to reach out to the community as much as possible and some families have come to us. Also when we've had maybe a bit of a hint or a gut feeling that a family is struggling, we've made the phone call and had that conversation.

A caring school leader is someone who builds a supportive environment (Näsman, 2018, p. 521); demonstrates approachability (Edge et al., 2016, p. 2) and authenticity (Louis et al., 2016, p. 310); it is evident that these three school leaders were keen to support by encouraging families to contact them. Emily had also identified vulnerable children who were invited to attend the school hub to support them in "their nurture and well-being" and planned care for those who could not.

If they're not coming into the hub we have a system where we know they're getting their lunch, a hot lunch or cold lunch, food parcels. We're doing a phone call, a weekly phone call or text. 
It is interesting to note that Mhàiri identified that families and her pupils needed some reassurance and describes making a video for them before closing the school, as emotional:

So that video message which was quite emotional cause I kind of closed the doors for the last time and put a wee notice on, and I had my wee mascot and all that kind of thing as well. It was really needed to calm and reassure families too.

According to Noddings, emotions are an ingredient of the relational need in caring for others, a natural drive within. Related to this, Edge et al. (2016) suggest that "support and understanding" are key aspects of caring leadership; similarly, Louis et al. (2016, p. 310) cite "attentiveness" and "authentic knowledge of others" within their research on caring leadership. Mhàiri expressed the need to respond to families emotionally as they were showing emotion to her. She adds, "My role in interacting with families now needs to be a very calm and reassuring role" and at one point reports that she actively decided to respond to some harsh criticism by addressing the anxiety behind the angry spoken words. Agnes empathised with the pressures on a member of staff and helped the teacher prioritise her own family when the latter felt overburdened by work, thus showing care by ensuring school expectations of workload were reasonable for them:

The teacher was feeling pressurised to be on Seesaw [online platform for student engagement] all day. I basically put a stop to it. I said, you guys basically post once in the morning and, you know, you go and deal with what you have to deal with and then, you know, perhaps you spend half an hour looking at what people have posted to you the night before. . You're not to spend your whole day on this.

Yvonne Näsman (2018, p. 521) recognises a caring leader as someone who supports and encourages, knowing what is needed for others to manage. These are all examples of listening. The three head teachers in their unique way were listening to what the families, the children, as well as teachers were "going through" (Noddings, 2012b, pp. 773-4) and experiencing. The Head Teachers further realised that some families are more vocal than others who can be silent, for various reasons, and made efforts to reach out in other ways, such as through Parent Councils, and also informally, using the community grapevine.

Noddings (2013, p. 112) makes a clear distinction between caring about and the act of caring for. Rejecting the notion of "universal caring," she allows only that one can "care about" everyone. . . [by] maintaining an internal state of readiness to try to care for whoever crosses our path. But it is different from the caring-for to which we refer when we use the word 'caring"' (1986, p. 18). The school leaders interviewed undoubtedly care for and this is clear from the actions of care. Mhàiri actively encouraged expressed needs to be voiced, reflecting that "pastoral care is becoming difficult because the human contact isn't there." This will be discussed further in the next section.

Clear links are also made between how a person loves and cares for another to their own experiences of being cared for
Noddings (2006, p. 524). She describes caring as a moral way of life (Noddings, 2012a, p. 54). An assumption can be made here about these Head Teachers; that they know what it means to care and be cared for, and that it has become part of their own humanness and not separate from their leadership role. "Caring is a worthy human endeavour" is one of the reasons presented by Smylie et al. (2016, p. 3) to the query why we should care about caring. In their responses and manner, it is easy to conclude that these leaders care for and not only about. Mhàiri describes an outing with an upper school child during lockdown and we note here that she expresses "I'm not a fan of farms or zoos" yet values the need it meets for the child: "This is more valuable than us forcing him to be in his classroom writing with his classmates." This is an interesting example to consider around assumed need, expressed need and how a Head Teacher meets these. Kindness plays a part here too. Mhàiri does not merely offer a trip out but actively pursues an approach to emotionally engage the pupil with the outing. Knowing that this pupil has not left their home in four weeks, she visits their home staying outside, noting that "what was really important was that he saw us." She gives him a letter, makes a personal telephone call to him prior to the trip, pays attention to detail, and buys his favourite snack for the outing:

There's a risk that he's not going to come but I know he likes the nuts and pretzels so I'm phoning and saying, "I'm going to meet you at the school at 10.40. I've got the nuts and pretzels, they're the ones that you like. We can eat them in the taxi."

Kindness is underpinned by compassion, benefits others, and builds trust (Kerr et al., 2014, p. 20). When discussing transition Mhàiri is also aware of looking at how to bring "warmth" to this process despite it being online. We remind readers of Noddings (2012b, p.777) description of the caring climate in the beginning of this paper as being underneath all that we do as teachers and that when this is in place "everything else goes better," and we suggest that the caring actions discussed in the interviews support this stance. Noddings (2005, p. 17) notes that there is no formula to caring and "caring is a way to being in relation, not a set of behaviours." The school leaders have responded differently to whatever need is expressed or assumed. Agnes's smaller school community meant that she could organise staff who are already connected with children to support them and within this, staff had autonomy of deciding what this support looked like.

Noddings further describes caring leaders as those who involve others to take part and support ideas others might like to take on (Noddings, 2006, p. 344). It was clear in the interview with Emily that this was her own caring approach to leadership. She spoke warmly about her staff and gave examples of how she valued them by giving opportunities to lead.

Massive opportunities have come through so for example in terms of leadership in the school, there are lots of members of staff taking on leadership roles from teaching assistants to class teachers.

She describes a teacher who took on the role of ensuring children and families were supported with use of technology for 
home learning and how it was something she wanted to do and has co-ordinated and fed back. A teaching assistant is described as "achieving things she never thought she'd be able to do." Emily involves others and she refers to her school as "an amazing school with amazing staff," her actions reflecting that of a caring school leader who creates a culture where love is shown to the school staff team and where staff know they are valued and have potential (Näsman, 2018). Those interviewing Emily noted her wish to support her staff to grow and found this reflected in Noddings' writing: "that the concept of love, used in the context of caring, is connected to the carer's wish for the cared-for to grow" (Noddings, 1986, p. 78). Emily expresses joy at the success that staff have had in supporting the children during this time through taking on leadership roles, saying that she is "amazed at some of the learning conversations that are coming through":

I think there are also massive opportunities that have come through, so for example in terms of leadership, $\mathrm{X}$ is a school where there are lots of people that are taking leadership opportunities from learning assistants to teaching staff... It's different people that are coming through.

\section{Connection and Communication}

Communication is essential for the expressed need to be heard and read. The extent to which the expressed need can be met may be affected by the level of connection which exists between caredfor and carer. In addition to the carer responding to expressed needs, an acknowledgement of the act of care from the caredfor is required to complete the care relation (see Bergmark and Alerby, 2006, p. 12; Noddings, 2012b, p. 773). In order for both these conditions to be met then, two-way connection and communication are essential (Gilligan, 1993, p. 62).

This is usually relatively easy in schools, through regular faceto-face interaction whereby teachers connect and communicate with the pupils they are caring for directly and can "tune in" to pupil's verbal and non-verbal cues, as well as readily receiving their feedback to the care offered (Bergmark and Alerby, 2006, p. 12). The ethos of care which is embedded in the Scottish curriculum pre-COVID-19 is buttressed when considering Scottish policy such as GIRFEC (Scottish Government, 2008) which highlights the importance of connection and communication further, not only with the pupil but with their wider ecosystem (Bronfenbrenner, 1979). The importance of context is recognised by Maggie FitzGerald (2020) who states that care "is distorted if abstracted from particular contexts and specific relations" (p. 252), a notion also recognised by Agnes:

Pastoral care is becoming difficult because the human contact isn't there and a lot of what you do when you are dealing with situations of separations or poverty or domestic violence you offer a level of empathy which doesn't happen in a phone call, it's harder. . That's been the hardest thing throughout COVID-19, maintaining those little relationships with children.

Noddings (2013) acknowledges ideal conditions for relational care are not always possible:
When something goes wrong (or might go wrong) in our relational encounters, we want to restore or maintain natural caring. To do this, we draw on what I have called our "ethical ideal," our memories of caring and being cared for. We ask how we might act if this other were not so difficult, if the situation were less complicated, if the burdens were not so great, if we were at our caring best. (p. xvi)

During the lockdown, Head Teachers seem to have drawn on these ethical ideals in order to maintain or re-establish the connections and communications which would occur in the school setting. Given the unprecedented situation, this appears to have involved creative thinking and approaches, which relates to Smylie et al. (2016) prerequisites to care: "aims, positive virtues and mindsets and competencies" (p. 8) which can be considered in addition to those previously discussed by Noddings. A specific mindset discussed was "playfulness," described as capturing "dispositions of creativity, inventive thinking, flexibility, and adaptability," all of which were evident in the Head Teachers' approaches to maintaining, or at times re-establishing connection and communication. In an effort to reconnect with a child, Mhàiri wrote a letter which requested the child's "help" the following day and accompanied this letter with a gift when she handdelivered this. This allowed an opportunity both for face-toface connection, which would otherwise not have been possible during the lockdown, and also accounted for time for the act of care to be processed by the child.

Mum said that he hadn't been out of the house for four weeks, refused to get out of the house. So I said, let me see if I can get my place at the farm. So I got my place and I phoned the mom. And I'm thinking about it and I thought, right, if she says to him: "You know, you've got place at the farm," he's not going to go, right? So I thought, well, I could maybe just like you know phone him. Anyway what I ended up doing was going down to his house, obviously social distancing in his driveway, wrote him a letter, and put a chocolate bunny inside it and I said that I needed kind and helpful people to help with the animals at the farm and I thought about him and would he be able to help me. He ran away with the letter and then he came back and he's hiding behind his mum and he's kind of nodding his head. So what I did was, I said OK, what I'm going to do is I'm going to leave my car here. I'm going to leave my car safe with you and I'm going to pick up tomorrow and we're going to the farm, right? So, I went in the morning and we go to the farm. It's the first time he'd been out in over 4 weeks.

The head teacher returned the following day, creating space for the act of care to be acknowledged and thus the care relation was completed. This creative approach was essential in re-establishing connection and communication which ordinarily would have occurred naturally in the school setting. Similarly, Emily discussed creative ways to re-establish or maintain connection and communication with pupils and families through home visits under the guise of delivering lunches: 
Our staff go out and deliver a lunches and they are on a rota, and actually it's really important because that's some of the checks we have got with those families, it doesn't feel as if you are necessarily checking up on them but in fact we are. It's a pastoral visit as much as anything.

Agnes also outlined challenges in terms of finding alternatives to face-to-face communication, while highlighting flexibility in overcoming these difficulties: "Technology we got round by providing the school laptops to anyone that didn't have reasonable access." In this way, there was a recognition of the changing face of care in this setting, where face-to-face interactions within school settings were impossible, alternative opportunities for connection and communication were created by the head teachers both with and without technology. In addition to caring for the pupils, Mhàiri discussed being able to respond to families' expressed needs through the use of technology: when discussing the families having an "emotional response" to an online parent council meeting, she acknowledged "the reaction from the families, it was an emotional reaction, so I now need to respond to them emotionally as well."

Another idea which has emerged includes the efforts to maintain and strengthen connection and communication involving the cared for seeing and hearing from the carer. This may relate to Immanuel Levinas' idea of the importance of seeing the face of "the Other," whereby the face of the other connects and contracts us to behaving to a certain standard towards the other (Blond, 2016). For example: even out with direct interactions, Mhàiri recognised the importance of visual representations of the carers and ensured pictures of school staff members were stuck into learning packs which were sent home during lockdown period. She further referenced the use of technology, specifically Microsoft Teams "so we can actually have video chats," while Emily facilitated doorstep garden visits from the Additional Support for Learning teacher to some children.

Despite some of the potential barriers to care which were captured during the interview process, evidence of creative measures to ensure connection and communication, and ultimately care, were apparent from head teachers to pupils, families, and staff members. In terms of meeting the prerequisites of care, it has been suggested by Smylie et al. (2016):

Caring is more than the sentiment, but the way in which this is enacted, the motivations behind it and the relational context within which care takes place. (p. 7)

The promotion of connection and communication, regardless of the medium used, was a recurring theme in the interviews:

Mhàiri: "Our whole kind of ethos through this is the children need to feel connected to us whether or not they are hearing us or they are seeing us."

Agnes: "On the SeeSaw app they can message the teacher and they can also post pictures of what they have been doing."
Emily: "even if it is once a week for a circle time, or they bring their juice and a biscuit and they come together or the teacher goes in and reads a story."

\section{Community}

Thomas Sergiovanni (1999) outlines the defining features of community within schools; joining and connecting people around a purpose, with little emphasis on external pressures and more on shared local values. Community suggests humanity in common; a meeting of hearts and not just minds. Sergiovanni sees an organic community which grows away from individuality and embraces the collective sensitivities of community development. This representation of community seems very different from the reciprocal and individual care envisaged by Noddings (2013), where there is a necessary acknowledgement of care given and received. This distinction becomes more apparent as school leaders increasingly move from direct one-to-one care to the strategic role. Such a role seems to challenge Noddings' insistence on the intimate nature of emotion in a caring role (Noddings, 2012a).

Nodding, in an essay On Community (1996), questions the need to develop communities. While she argues that communities support a "human longing to belong" (p. 250), they nonetheless cannot escape what she terms the "dark sides", the two poles of liberalism and communitarianism as possible foundations for communities. Liberal approaches, such as that developed by John Rawls, focus on atomistic universal justice, with justice ethics often represented through masculine practices that treat humans as "classifiable and comparable objects instead of unique beings" (see Noddings, 1986; Schutz, 1998, p. 373). Liberal approaches are concerned with "formal rules and rights" that emphasise negative duties, that "has eroded not only a sense of responsibility for one another but even our understanding of human sociality" (Noddings, 1996, p. 252). Yet, similarly communitarianism is equally dangerous, writes Noddings, where "communitarian models threaten to create societies where the individual is lost in a mass subjectivity" (Schutz, 1998, p. 374). The question is what is that "glue" (Noddings, 1996, p. 254) that holds people together without falling to the dark side? Noddings' suggestion is that the core of community could be founded on care: "non-violence and care... may provide a center for community" (Noddings, 1996, p. 267), as "caring-a commitment to receptive attention and a willingness to respond helpfully to legitimate needs - is not likely to allow great causes to displace it" (p. 267).

Indeed, Nodding suggests that care can draw people together when a threat arises. We are seeing the pandemic and school closure as this threat and part of the school's response is the formation of communities based on care (indeed, Mhàiri calls it "kindness"). Louis et al. (2016) write about care "filtering down" as the caring leadership brings about caring staff. During the interviews conducted, the reduction in the opportunities for direct care did not appear to diminish the obligation to care, and in most cases, neither the desire, as stated by Emily: "I am committed to care for those people who don't have."

It is thus not surprising that an increase in community engagement was highlighted in the interviews, alongside a new 
awareness of shared understanding around the caring functions of both school and home. In all cases, the sense of community was enhanced by additional virtual meetings with parent bodies such as the Parent Council, as well as with individuals. Mhàiri recounts how she encouraged a parent in a vulnerable situation who could not communicate during the day time to telephone her at any time: "I had a phone call with a parent one night at 11 o'clock. ...the only time she could speak to me." Although increased connection with families may have been intended as an effective means of communication, in practice, Head Teachers became more aware of the challenges facing families during lockdown than they have previously been. Some parents and carers openly shared their struggles and were uninhibited as they expressed their vulnerabilities. In return, Head Teachers frequently went beyond their normal remit and followed up on personal or even financial concerns, making pastoral phone calls and even showing a willingness to reveal their own fragilities: "my husband has compromised immunity...some pupils I worked with displayed signs of COVID. . .my husband is staying away because he is shielding" (Emily). The generous actions of both the Head Teacher and her husband allowed the intimate work with children to continue in the learning hub. Head Teachers were open in their discussion of family and personal health concerns and caring responsibilities. At times, the seriousness of the COVID-19 situation was offset by planned, light hearted icebreaker activities such as a staff assembly dance video: "at the end of every assembly, the teachers do a dance. . like Agadoo or Superman. ...the children need to feel connected, whether they are seeing us or hearing us" (Mhàiri). The school communities seemed to rally to support Head Teachers in their identification with and recognition within the locality (Noddings, 2004).

When considering immediate care, Emily discussed how during lockdown, she worked directly with a community group supplying hot meals to vulnerable families. "We have a hot meal twice a week. It is cooked at a local club. We pick them up and help deliver them to families." This understated, handson care recognised the loss of the statutory provision of a free school meal for every child in primary 1 to primary 3 (and to other children by means testing) and working with community volunteers, attempted to fill this gap, at least with two regular hot meals per week. Head Teachers were also called upon to offer informal counselling to families, even making themselves accessible via text or e-mail, well beyond the school day "The families e-mail me or message me and I know exactly how many are going to turn up at the Hub each day" (Agnes). In all cases, the need to reassure families became a notable feature of care, whether defined as natural or ethical. A more intimate leadership style was seen to emerge from the pandemic, one in which an emerging use of new technology and refreshingly honest attitude to shared vulnerability became the norm: "Every family has their own situation and all we can do is [support]" (Agnes). Another Head commented about the misunderstandings that can emerge from the current stress and for poorly used technology for communication: "If that had been me speaking to the parent in the playground instead of through email, it would have been dealt with immediately" (Mhàiri). One passing comment was particularly revealing: "You do notice these inequalities, in terms of who has computers, and who has broadband, and who is needing food parcels. You can see that really clearly now in the current crisis" (Emily).

Head Teachers seemed to be demonstrating vicarious care by setting the tone for the organisation, by distributing responsibility for care to others and on occasion, by directly engaging in one-toone support which goes beyond what is usually understood as the Head Teachers' role. It appears that there is a constant negotiation between the necessity of strategic leadership and the immediate demands for individual reciprocated care. By developing a strategic focus towards the whole school community, school leaders showed a default ethos of care both within school and outward facing towards the wider community. As leaders, they utilised their human resources to overtake this caring aim, whilst being selective about the appropriateness or otherwise of direct engagement with individuals. Common to all interviews was the sense of a natural recourse to care. It appeared to bring to Head Teachers, a welcome return to the intimate values of classroom practice and a momentary break from their role as highly accountable Head Teachers within a Local Authority structure, possibly leading to "happiness" (Noddings, 2004, p. 222) which emerges from caring participation. It should not be surprising that these dual demands create a tension within Head Teachers; the natural "empathy" (Slote, 2007, p. 211) that involves both understanding and feeling, versus the functional demands of leading a complex organisation "When you are dealing with situations, like separation, or poverty, or domestic abuse, you are able to offer a level of empathy that doesn't happen often" (Mhàiri).

Referring to Kierkegaard, Noddings (2013, p. 14) considers care to be a disturbance of one's own "ethical reality", that is, to move a person from what they know is ethically right, to what they actually feel to be right. The carer is moved to reduce the element of discomfort or hurt felt by the cared for. As mentioned earlier, it is at this cross-section of caring and acceptance of care that a relationship is formed, what Noddings (2013, p. 30) refers to as, "engrossment." One particular challenge to this relationship may, however, be the impact of community itself. Whilst developing a community ethos, Head Teachers frequently oversee a strategy to enhance community. The necessity of strategy (including distribution of leadership to others) may result in them having to limit the number of direct relationships within the community itself. In a large school, development of these relationships may require reliance upon other staff, as explained by Emily, one of the Head Teachers, so that the overall aim is met. This is often achieved by purposely limiting their enjoyment of "feeling with" personal community relationships what Noddings (2013, p. 30) sees as being critical to care itself. In this recent time of COVID-19, the strategic void that was previously experienced was possibly filled in these times of crisis and emergency. Thus, our school leaders were often seen with their sleeves rolled up; physically distributing food, dropping in to visit families or ensuring that individuals had the right resources to continue study at home. Running concurrently with these legitimate natural caring actions were aspects of ethical care where the home visits could be used to assess the welfare of children and thus fulfil the more statutory nature of care 
through Child Protection practices (Scottish Government, 2014) "It doesn't feel like we are checking up on them but in fact we are; we are doing a pastoral visit" (Emily).

The idea of service to the local community was mentioned several times by the Head Teachers who knew their communities well and showed great familiarity with the demographics of the catchment area. They were able to provide additional information that elaborated on national data; examples of hidden poverty, financial difficulties due to disintegrating relationships, knowledge of patterns of difficulties in homes and of health patterns that could impact children. There was a strong sense that the school was an integral part of the community, reaching to almost every section of the population. Although unstated, the Head Teachers interviewed proudly identified with their school communities whilst also talking of the support the schools received from the local population "My families have a lot of faith in my leadership and a lot of confidence in what I am doing, but this goes up and down-and it will go up and down." Time, experience, and in some cases, educational resources were freely given as acts of service, clearly demonstrating integration of the school and community. This notion of service chimes with Marcel's "disposability" (Noddings, 2013, p. 19), with its characteristics of spending oneself as an investment in others. One Head Teacher discussed concerns about running out of energy and of fearfulness for colleagues who were already on the edge of burnout: "they either meet that challenge or they deflate and become insular, and I have seen this with a couple of my pals, my Head Teacher colleagues." There can be no doubt that Noddings' adoption of the caring term, "engrossment" (Noddings, 2013, p. 30) comes at a high cost to individuals in leadership positions, but it is unavoidable to professionals who understand that such care is a prerequisite to successful teaching and subsequently, foundational to effective leadership. In a very real sense, the school has become the village to which the local community gravitates for support and relationship: "We've got a good grasp of who is vulnerable; children and families in general" (Agnes). Head Teachers, by actions and policy, grant permission to the local community to be both recipients and providers of care. At the same time, change leaders also make themselves vulnerable and susceptible to hurt (Ackerman and Maslin-Ostrowski, 2004), a risk of intimate care within strategically focused leadership.

The question of the legitimacy of care in community remains a prominent one. According to Noddings' definition of care, the reciprocal element is missing when strategic caring actions take place without feedback to acknowledge the caregiver. Furthermore, the self-sacrificial nature (Zhang and Ye, 2016) of strategic leadership often removes the opportunity to experience the motivational sensation of helping a fellow human being directly-especially when this help is generously acknowledged with a responsive smile or a leap of joy. The Head Teachers interviewed each expressed a personal, genuine care for staff, pupils, families, and to a varying extent, the wider community. The importance of authenticity is highlighted in caring leadership literature (Louis et al., 2016, p. 310). The relational stimulation was often achieved though others, vicariously (Aspfors and Bondas, 2013) and indirectly yet the desire to experience the first-hand nature of relationship remained as a permanent feature. This in part would explain the hands-on approaches taken by these heads, doing work that appeared to contrast with their level of responsibility and even career grade. In essence, these Head Teachers understood that the holistic care of young people (Lovat and Toomey, 2009) does not diminish as promotion is gained; it is more likely that promotion is gained because these leaders never forgot the feeling of response that emerges from genuinely relational care.

\section{CONCLUSION}

The COVID-19 school closure provided a context for Head Teachers to attend to the needs of the different members of their school, whether they were part of the educational members, families, and children. This attention involved a number of "actions, concerns, utterances, and feelings that grow out of sensitivity and concern for the needs" (Gabriel, 2015, p. 323). This implies that care is not a virtue or attitude but a practice, "a species of activity that includes everything that we do to maintain, continue, and repair our 'world' so that we can live in it as well as possible” (Tronto, 1993, p.103; Gabriel, 2015, p. 323).

Care is fundamentally part of these three Head Teachers' identity. While there is extensive literature on Head Teachers and their caring role, the uniqueness of this article is that it reports the caring responses of Head Teachers in this unprecedented situation of school closure. Most literature assumes schooling, whereas in this context, schooling has been challenged. Indeed, the term home-schooling, used within a Scottish context, indicates a shift towards homes while trying to salvage some semblance of schools. Head Teachers were evidently challenged when the school building was removed from the equation, their concern chiefly based on their understanding that their teachers and families needed to be cared for in diverse ways. While making and executing plans to reach out to everybody, those with individual needs were nonetheless attended to, showing in these Head Teachers attention to the detail, listening to the situation, and taking action.

Notwithstanding the fluctuating speed of change during lockdown, and the lack of guidance from authorities, the Head Teachers demonstrated indomitable attentiveness, responsiveness, and responsibility for others, thus showing that relationships are fundamentally part of values within education which goes beyond schooling and are far more engrained than the neo-liberal performative discourse that often characterises our school practices. The decisions and actions of Head Teachers show that they shared the values underlying the aforementioned GIRFEC. It is in such moments that policies such as GIRFEC and the UNCRC are challenged in relation to where their foundational values lie, with relationships emerging as being fundamental to these policies.

We end this paper on a note which marks the process of the analysis of these interviews. While only able to have conversations discussing the theory and planning this writing 
online, due to the continued restrictions of the on-going pandemic, we, the authors, feel that these Head Teachers have united us in our admiration of their efforts and in our ardent wish to do justice to their accounts. While not attempting to generalise these experiences, we believe that some Head Teachers working in Scotland and beyond will identify with some of the issues discussed. The challenges seemed to offer these Head Teachers possibilities to find alternatives and go beyond what is considered as normal and within well-established systems and proformas. The uncertainty and otherness of the situation deconstructed their ways of doing and being, as this moment gave them a possibility to be-othered and therefore, become other to themselves in particular ways. They thus seemed to be offered another way of seeing, listening and being with others. We thus end the paper with a quote from one of the teachers interviewed in the research who described her Head Teacher in glowing terms:

The class teachers have been keeping a record of all the children that are engaging daily and by the Thursday if there are certain children that have not been engaging, our Head Teacher would then either phone the child, if she's not heard from him that week or she would go to their door and then she'll then feedback to us and say such and such is okay. I saw them or I spoke to mum or I spoke to the child and they've just not engaged this week cause of blah blah. So our

\section{REFERENCES}

Ackerman, R. H., and Maslin-Ostrowski, P. (2004). The wounded leader and emotional learning in the schoolhouse. School Leadership Manag. 24, 311-328. doi: 10.1080/1363243042000266945

Aspfors, J., and Bondas, T. (2013). 'Caring about caring: newly qualified teachers' experiences of their relationships within the school community'. Teachers Teaching Theory Practice 19, 243-259. doi: 10.1080/13540602.2012.754158

Bergmark, U., and Alerby, E. (2006). Ethics of care - a dilemma or a challenge in education. JOUR 2006, 27-30.

Blond, L. (2016). 'Levinas, Europe and others: the postcolonial challenge to alterity'. J. Br. Soc. Phenomenol. 47, 1-16. doi: 10.1080/00071773.2016.1180848

Bronfenbrenner, U. (1979). The Ecology of Human Development: Experiments by Nature and Design. Cambridge, MA: Harvard University Press.

Coles, E., Cheyne, H., Rankin, J., and Daniel, B. (2016). 'Getting it right for every child: a national policy framework to promote children's well-being in scotland, united kingdom. Milbank Q. 94, 334-365. doi: 10.1111/1468-0009.12195

Edge, K., Descours, K., and Frayman, K. (2016). Generation X school leaders as agents of care: leader and teacher perspectives from toronto, New York city and london. Societies 6:8. doi: 10.3390/soc6020008

FitzGerald, M. (2020). 'Reimagining government with the ethics of care: a department of care.'. Ethics Soc. Welfare 14, 248-265. doi: 10.1080/17496535. 2020.1746819

Gabriel, Y. (2015). The caring leader - what followers expect of their leaders and why? Leadership 11, 316-334. doi: 10.1177/1742715014532482

Gilligan, C. (1993). In a different voice: Psychological theory and women's development. Cambridge, MA: Harvard University Press.

Hayes, N. (1997). "Theory-led thematic analysis: social identification in small companies," Doing Qualitative Analysis in Psychology (London: Psychology Press).

Hollway, W. (1989). Subjectivity and Method in Psychology: gender, meaning and science. London: Sage Publications.

Hollway, W., and Jefferson, T. (2000). Doing Qualitative Research Differently. London: Sage Publications.
Head Teacher is making sure that we are engaging or every child is at least being contacted and has given contact back. Just for, you know, to make sure the children are safe. For some of our children, you know, school was the only safe place. She [Head Teacher] is absolutely amazing.

\section{DATA AVAILABILITY STATEMENT}

The datasets presented in this article are not readily available because the dataset is only available to the research team. Requests to access the datasets should be directed to DM, dmercieca001@dundee.ac.uk.

\section{ETHICS STATEMENT}

The studies involving human participants were reviewed and approved by the School of Education and Social Work, University of Dundee. The patients/participants provided their written informed consent to participate in this study.

\section{AUTHOR CONTRIBUTIONS}

All authors listed have made a substantial, direct and intellectual contribution to the work, and approved it for publication.

Kerr, S. L., O’Donovan, A., and Pepping, C. A. (2014). 'Can gratitude and kindness interventions enhance well-being in a clinical sample?'. J. Happiness Studies 16, 17-36. doi: 10.1007/s10902-013-9492-1

Kilbrandon, L. (1964). The Kilbrandon Report: Children and young persons Scotland. Edinburgh: Scottish Home and Health Department \& Scottish Education Department.

Louis, K. S., Murphy, J., and Smylie, M. (2016). 'Caring leadership in schools: findings from exploratory analyses'. Educ. Admin. Q. 52, 310-348. doi: 10.1177/ $0012161 X 15627678$

Lovat, T., and Toomey, R. (2009). Values Education and Quality Teaching The Double Helix Effect, 1st Edn. Dordrecht, Netherlands: Springer.

McLennan, C., Mercieca, D., and Mercieca, D. P. (2020). What can I do? Caring relationships among teachers, students and families during COVID-19 lockdown in Scotland. Malta Rev. Educ. Res. 14, 163-181.

Näsman, Y. (2018). The theory of caritative leadership applied to education. Int. J. Leadership Educ. 21, 518-529. doi: 10.1080/13603124.2017.1349183

Noddings, N. (1986). Caring: A relational approach to ethics and moral education. Berkeley, CA: University of California Press.

Noddings, N. (1996) On Community. Educ. Theory 46. doi: 10.1111/j.1741-5446. 1996.00245.x

Noddings, N. (2004). Happiness and Education. Cambridge, England: Cambridge University Press.

Noddings, N. (2005). The challenge to care in schools: an alternative approach to education. London: Teachers College Press.

Noddings, N. (2006). 'Educational leaders as caring teachers'. School Leadership Manag. 26, 339-345. doi: 10.1080/13632430600886848

Noddings, N. (2012a). The language of care ethics. Knowledge Quest. 40, 52-56.

Noddings, N. (2012b). The caring relation in teaching. Oxford Rev. Educ. 38, 771-781. doi: 10.1080/03054985.2012.745047

Noddings, N. (2013). Caring: A Relational Approach to Ethics and Moral Education, 2nd Edn. Berkeley, CA: University of California Press. doi: 10.1080/03054985. 2012.745047

Rogers, C. (2001). A therapist's view of psychotherapy - On becoming a person. London: Constable. 
Schutz, A. (1998). Caring in schools is not enough: community, narrative and the limits of alterity. Educ. Theory 4, 373-393. doi: 10.1111/j.17415446.1998.00373.x

Scottish Government (2008). Getting It Right For Every Child. Available Online at: https://www.webarchive.org.uk/wayback/archive/20170104102702/ https://www2.gov.scot/resource/doc/1141/0065063.pdf (Accessed October 5, 2020)

Scottish Government (2014). National Guidance for Child Protection in Scotland. Available Online at: https://www.gov.scot/publications/national-guidancechild-protection-scotland/ (Accessed October 5, 2020)

Scottish Government (2016). A Plan For Scotland 2016-17. Available Online at: https://www.gov.scot/binaries/content/documents/govscot/publications/ strategy-plan/2016/09/plan-scotland-scottish-governments-programmescotland-2016-17/documents/00505210-pdf/00505210-pdf/govscot\% 3Adocument/00505210.pdf (Accessed October 5, 2020).

Scottish Government (2018). Thematic Inspection of Personal and Social Education/Health and Wellbeing in Scotland's schools and Early Learning and Childcare Settings. Available Online at: https://education.gov.scot/Documents/ EducationScotlandPSEReportAug2018_.pdf (Accessed February 16, 2021).

Scottish Government (2021). Scottish Attainment Challenge. Available Online at: https://education.gov.scot/improvement/learning-resources/scottishattainment-challenge/ (Accessed February 16, 2021).

Sergiovanni, T. J. (1999). Building Community in Schools. London, England: JosseyBass.
Slote, M. (2007). The ethics of care and empathy. London, England: Routledge. Smith, M. (2013). Forgotten connections: reviving the concept of upbringing in Scottish child welfare. Scott. J. Resid. Child Care 12, 13-29.

Smylie, M., Murphy, J., and Louis, K. S. (2016). Caring school leadership: a multidisciplinary, cross-occupational model. Am. J. Educ. 123, 1-35. doi: 10. $1086 / 688166$

Tronto, J. C. (1993). Moral Boundaries: A Political Argument for an Ethic of Care. New York, NY: Routledge. doi: 10.1086/688166

Zhang, H. B., and Ye, M. L. (2016). A literature review of self-sacrificial leadership. Psychology 7, 1205-1210. doi: 10.4236/psych.2016. 79121

Conflict of Interest: The authors declare that the research was conducted in the absence of any commercial or financial relationships that could be construed as a potential conflict of interest.

Copyright (C) 2021 Ferguson, McKenzie, Mercieca, Mercieca and Sutherland. This is an open-access article distributed under the terms of the Creative Commons Attribution License (CC BY). The use, distribution or reproduction in other forums is permitted, provided the original author(s) and the copyright owner(s) are credited and that the original publication in this journal is cited, in accordance with accepted academic practice. No use, distribution or reproduction is permitted which does not comply with these terms. 